\title{
FABRICATION OF MICRONEEDLES
}

\author{
Yu-Tang Chen \\ Department of Mechanical Engineering, De Lin Institute of Technology, Taipei County, Taiwan 237, R.O.C, \\ ytang.chen@msa.hinet.net \\ Chin-Chun Hsu \\ Department of Mechanical and Electro-Mechanical Engineering, Tamkang University, Taipei County, Taiwan 252, \\ R.O.C. \\ Chieh-Hsiu Tsai \\ Department of Mechanical and Electro-Mechanical Engineering, Tamkang University, Taipei County, Taiwan 252, \\ R.O.C. \\ Shung-Wen Kang \\ Department of Mechanical and Electro-Mechanical Engineering, Tamkang University, Taipei County, Taiwan 252, \\ R.O.C.
}

Follow this and additional works at: https://jmstt.ntou.edu.tw/journal

Part of the Engineering Commons

\section{Recommended Citation}

Chen, Yu-Tang; Hsu, Chin-Chun; Tsai, Chieh-Hsiu; and Kang, Shung-Wen (2010) "FABRICATION OF MICRONEEDLES," Journal of Marine Science and Technology. Vol. 18: Iss. 2, Article 10.

DOI: $10.51400 / 2709-6998.2323$

Available at: https://jmstt.ntou.edu.tw/journal/vol18/iss2/10

This Research Article is brought to you for free and open access by Journal of Marine Science and Technology. It has been accepted for inclusion in Journal of Marine Science and Technology by an authorized editor of Journal of Marine Science and Technology. 


\section{FABRICATION OF MICRONEEDLES}

Acknowledgements

This work was supported by the National Science Council of Taiwan, Republic of China under contract NO. NSC-95- 2221-E-237-004. 


\title{
FABRICATION OF MICRONEEDLES
}

\author{
Yu-Tang Chen*, Chin-Chun Hsu**, Chieh-Hsiu Tsai**, and Shung-Wen Kang**
}

Key words: microneedles, V-groove, SU-8, fast-etching planes.

\begin{abstract}
This research utilizes two kinds of materials to fabricate the ideal shape of microneedles, polymer microneedles and silicon microneedles, with $236 \mu \mathrm{m}$ and $350 \mu \mathrm{m}$ in height respectively.

First, we utilize the turning model technique to fabricate the polymer microneedles. The silicon wafer with $\mathrm{V}$-groove is used as the model and the SU-8 2050 is the main material of microneedles. In addition, we also use the silicon as the material and adopt the wet-etching technology to make the silicon microneedles. By the characteristics of anisotropic etching and undercut, the silicon wafer will have the fast-etching plane and form the shape of microneedles.

In the final, all the microneedles will be tested on the artificial skin and the results show that the test reagent can permeate into the artificial skin uniformly. We expect the experiments will provide advantage for the bio-medicine technology in the future.
\end{abstract}

\section{INTRODUCTION}

Micro-Electro-Mechanical System, MEMS, is a diverse technology, and its foundation and application includes the light, mechanism, electricity, materials and physics and so on. However, the application of the polymer material has become more and more popular under the development of the MEMS technology.

Recently, because of the great progress of the science and technology, people not only concern how to remedy the diseases, but reduce the pain of a course of treatment. Microneedles have become a new type of the bio-medicine injector, it can throw the cuticle and not excite the nerve, and the patient will feel nothing. Moreover, it can be made by different kind of materials, like as SU-8, PMMA, PDMS, COC, silicon etc.

Guerin et al. [1] is the first people to build the microchannel with the SU-8 by surface micromachining and setup several

Paper submitted 10/10/08; revised 04/13/09; accepted 06/05/09. Author for correspondence: Yu-Tang Chen (e-mail: ytang.chen@msa.hinet.net).

*Department of Mechanical Engineering, De Lin Institute of Technology, Taipei County, Taiwan 236, R.O.C.

**Department of Mechanical and Electro-Mechanical Engineering, Tamkang University, Taipei County, Taiwan 251, R.O.C. thermal sensors in it; it starts the application of the SU-8. Lin and Pisano [5] utilizes the bulk and surface micromachining on silicon wafer with the height $1,3,6 \mathrm{~mm}$, respectively; it includes the microchannels and enhances the strength of the holder to make the structure of microneedles stronger. Kim et $a l$. [3] use the SU-8 negative photoresist and multiple backside exposure to create the height $200 \sim 400 \mu \mathrm{m}$ microneedles on the glass and sputter a layer of the metal. In the same year, Gardeniers et al. [2] present to employ the DRIE and $\mathrm{KOH}$ anisotropic wet-etching to fabricate the microneedles. Next year, Kuo and Chou [4] utilize the SU-8 negative photoresist and PDMS make the microneedles array and the SU-8 is the main structure for the PDMS shaping. Besides, Paik et al. [6] adopt the silicon wafer to make the microneedles as the cantilever beam and combine the PDMS in the same year. This structure includes the microchannels and microneedles and it utilize the tube to deliver the drug. Wilke et al. [7] calculate the etching rate on the different direction of the silicon wafer and put it under the accurate position, collocates the $\mathrm{KOH}$ anisotropic wet-etching to fabricate the microneedles array with octahedral structure. In MEMS 2006, J. M. Lippmann et al. presented the new process via polymer investment modeling to build the microneedle array with $160 \mu \mathrm{m}$ width and $280 \mu \mathrm{m}$ length.

\section{DESIGN THEOREM}

The structure of the human skin includes viable epidermis $(100 \sim 300 \mu \mathrm{m})$, dermis and hypodermis. Therefore, the main design of the microneedles is to destroy the viable epidermis and the length should be longer than $300 \mu \mathrm{m}$. Moreover, we also think over three basic factors to fill the bill, the staff (region 1), styles (region 2) and body structure (region 3) shown in Fig. 1.

Region 1 is design for the people to hold, region 2 is the key point that if the shape can pass through the skin and deliver the drug, at present the shapes are always monocline, trihedral, cone or cantilever beam, and region 3 can be devise as the hollow or substance structure, the hollow structure includes the microchannels and the drug can be delivered continuously. The substance structure, in the main, is to break the viable epidermis, and then the drug will permeate into the skin.

This research utilizes two kinds of materials to fabricate the ideal shape of microneedles, polymer microneedles and silicon microneedles. 


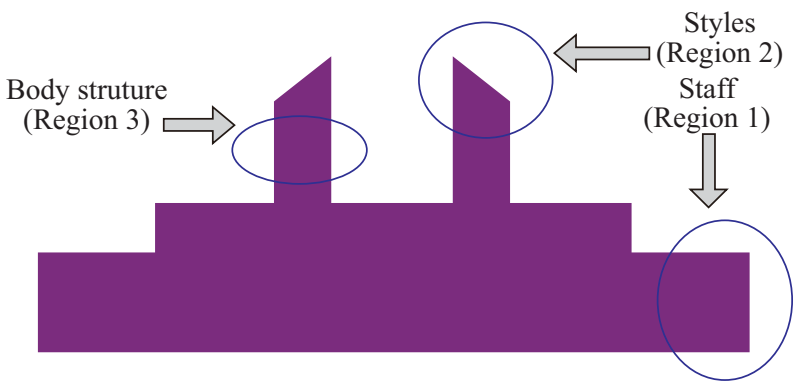

Fig. 1. The design of microneedles.

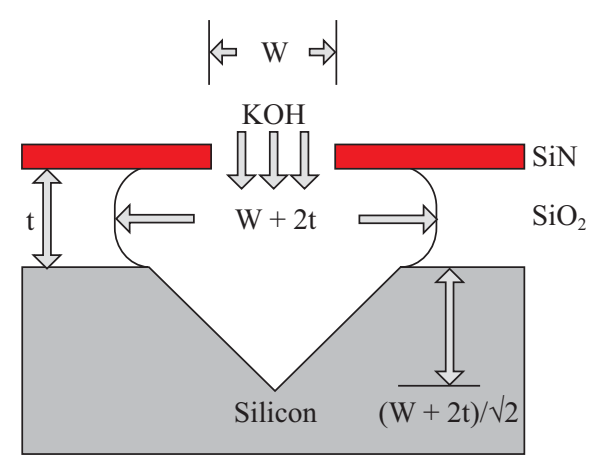

Fig. 2. The dimension diagram of V-groove.

\section{Polymer Microneedles}

First, this study utilizes the SU-8 2050 as the material of the microneedles. SU-8 is a high contrast, epoxy based photoresist designed for micromachining and other microelectronic applications. The UV-light absorptivity of SU-8 is lower than others and therefore can get the high-aspect ratio structures.

Because we adopt the turning model technique to fabricate the microneedles, we should consider the situation about the $\mathrm{V}$-groove on the silicon wafer.

According to the Miller index, the silicon wafer has several different types, $\{100\},\{111\}$, and $\{110\}$ and so on. We adopt the $\{100\}$ silicon wafer and use the different concentration $\mathrm{KOH}$ for anisotropic wet-etching to make the V-groove. Because the angle between the (100) and (111) is $54.7^{\circ}$, and the etching rate is $\mathrm{R}(100)>\mathrm{R}(110)>\mathrm{R}(111)$ (R: Rate), we can reserve the two adjoin (111) simply. The dimensions of the $\mathrm{V}$-groove can be design by (1), $w$ is the width of expose square, $t$ is the thickness of the oxide and considers the undercut we can obtain the depth, $x$, as shown in Fig. 2.

$$
\frac{x}{(w+2 t) / 2}=\tan 54.7^{\circ}
$$

The final design of polymer microneedles as shown in Fig. 3, the V-groove is $320 \mu \mathrm{m}$ square, the depth is $227 \mu \mathrm{m}$ and the staff is $0.5 \mathrm{~cm}$ square.

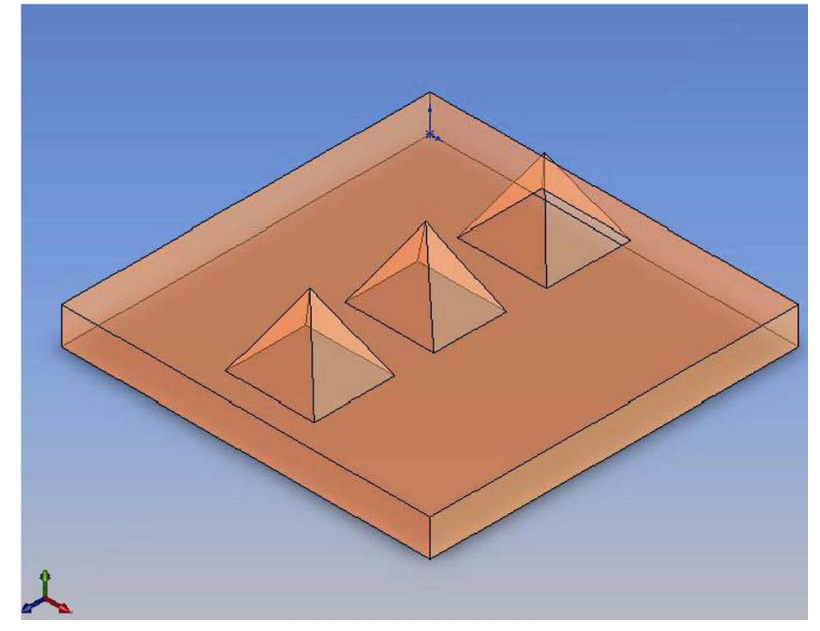

Fig. 3. The design of polymer microneedles array.

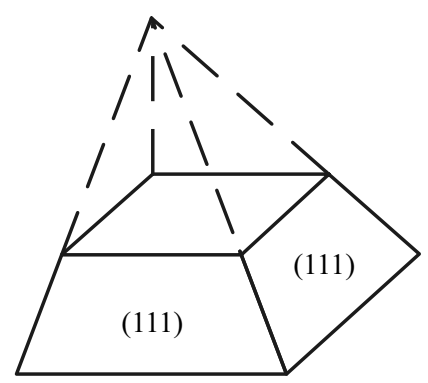

Fig. 4. Schematic illustration of КОН etching on silicon wafer.

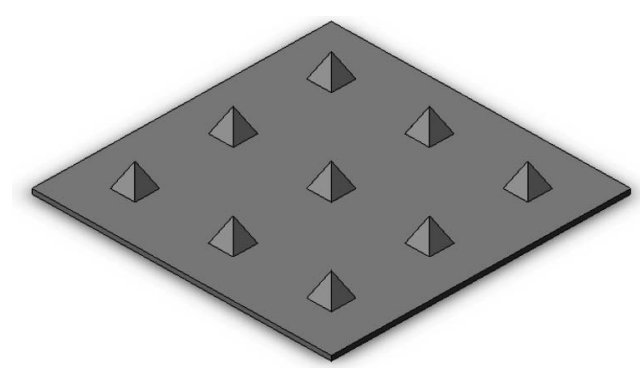

Fig. 5. The design of silicon microneedles array.

\section{Silicon Microneedles}

Except the polymer microneedles, we also utilize the silicon as the materials. This kind of microneedles is use silicon as the major material, and $\{100\}$ silicon wafer is good for wet-etching, we also choose the $\mathrm{KOH}$ as the etching solution with protection layer of nitride and oxide.

Rely on the silicon has different etching rate on diverse crystal orientation and the corner compensation, we can get four (111) planes with $54.7^{\circ}$ between the etched facet and the horizontal surface, as shown in Fig. 4. In the wet-etching period, the concentration of $\mathrm{KOH}$ is $30 \mathrm{wt} \%$ and the temperature is $80^{\circ} \mathrm{C}$. Figure 5 shows the design of silicon microneedles. 
Table 1. The crystal orientation with different etching solution.

\begin{tabular}{|c|c|}
\hline Crystal Orientation & Etching Solution \\
\hline$(110)$ & $\mathrm{KOH}, 40^{\circ} \mathrm{C}$ \\
\hline$(212)$ & $\begin{array}{c}30 \mathrm{wt} \% \mathrm{KOH}+25 \mathrm{wt} \% \text { propanol } \\
80 \% \mathrm{Hydrazine}+20 \% \mathrm{H}_{2} \mathrm{O} \\
\mathrm{KOH}+\mathrm{IPA}\end{array}$ \\
\hline (130) & $\mathrm{KOH}, 80^{\circ} \mathrm{C}$ \\
\hline$(331)$ & $\begin{array}{c}\text { EDP, EDPB } \\
30 \mathrm{wt} \% \mathrm{KOH}+25 \mathrm{wt} \% \text { propanol }\end{array}$ \\
\hline$(411)$ & $\mathrm{KOH}\left(15-50 \mathrm{wt} \% \mathrm{KOH}, 60-100^{\circ} \mathrm{C}\right)$ \\
\hline
\end{tabular}

The corner compensation is to avoid producing the non(111) planes, fast-etching planes, by the lateral etching in chief. In this research, we use $\mathrm{KOH}$ as the etching solution, the solution concentration is $30 \mathrm{wt} \%$ and the working temperature is $80^{\circ} \mathrm{C}$. With different etching solution, we can get the different Fast-etching planes, shows in Table 1.

\section{FABRICATION PROCESSES AND EXPERIMENTAL TEST}

\section{Polymer Microneedles}

At first, we will build the V-groove with the depth of 320 $\mu \mathrm{m}$ on silicon wafer, and then we'll coat the SU-8 on the silicon wafer with the depth of $450 \mu \mathrm{m}$ and use the scraper to put the SU-8 uniformly. Silicon wafer covered the SU-8 will be set in the oven to break away the bubbles and smooth the surface by heating and vacuum. Finally, we'll use the SU-8 developer to form the microneedles.

The series of fabrication processes contain the several steps as below and shown in Fig. 6 :

(1) Wafer cleaning: Mixing $\mathrm{H}_{2} \mathrm{SO}_{4}$ with $\mathrm{H}_{2} \mathrm{O}_{2}$ as the Piranha to clean the silicon wafer and heat it up at $150{ }^{\circ} \mathrm{C}$ to remove the mist.

(2) Depositing the oxide and coating the photoresist: The depths of oxide and photoresist are $1 \mu \mathrm{m}$ and $4 \mu \mathrm{m}$ respectively.

(3) Photolithographic: Utilizing the first mask to develop the V-groove.

(4) Remove the oxide and photoresist: Using the BOE and Acetone to remove the oxide and photoresist separately.

(5) $\mathrm{KOH}$ wet-etching: The $\mathrm{KOH}$ solution is $30 \mathrm{wt} \%$ and the temperature is set at $60^{\circ} \mathrm{C}$.

(6) Coating the negative photoresist, SU-8: The thickness of $\mathrm{SU}-8$ is $450 \mu \mathrm{m}$.

(7) The $2^{\text {nd }}$ photolithographic: This process develops the position of the bottom of microneedles.

(8) Departing the SU-8 from the silicon wafer: Put the silicon wafer in the MF-319 and the microneedles will move off the silicon wafer.

\section{Silicon Microneedles}

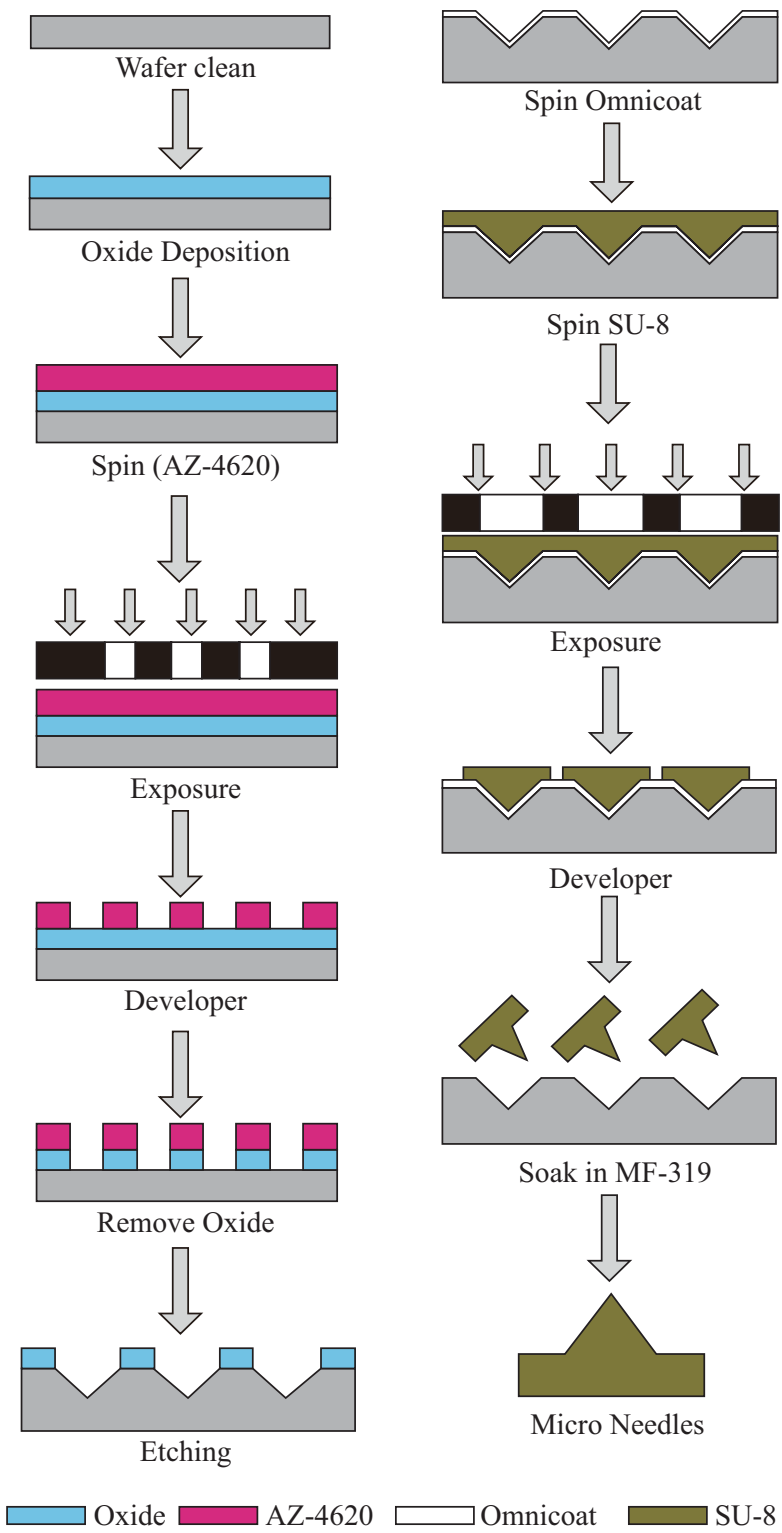

Fig. 6. The fabrication process of the polymer microneedles.

The other kind of microneedles is using the silicon as the material. By employing the characteristic of anisotropic etching to fabricate the substance microneedles we needed. The process listed as below and shown in Fig. 7.

(1) Cleaning the wafer to remove the hydrocarbon and the mist.

(2) Depositing the Oxide and Nitride with the depths are 1 and $0.2 \mu \mathrm{m}$ respectively.

(3) Coating the photoresist, AZ-4620.

(4) Photolithographic and develop the microneedles.

(5) Remove the unprotected Oxide and Nitride by Reactive Ion Etching, RIE.

(6) $\mathrm{KOH}$ wet-etching: The $\mathrm{KOH}$ solution is also $30 \mathrm{wt} \%$ at $80^{\circ} \mathrm{C}$. 

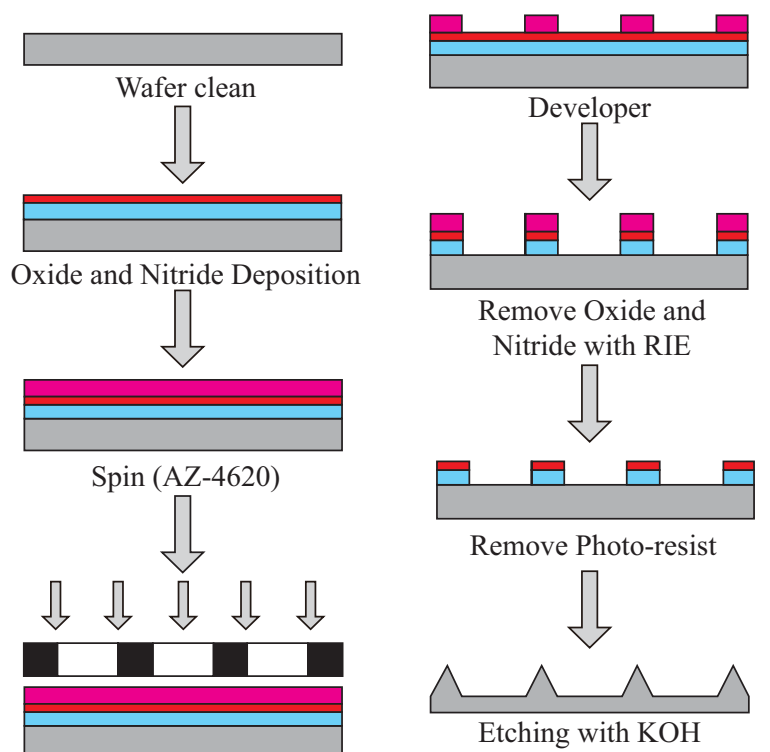

Exposure

$\square$ Oxide $\square$ Nitride

AZ-4620

Fig. 7. The fabrication process of the silicon microneedles.

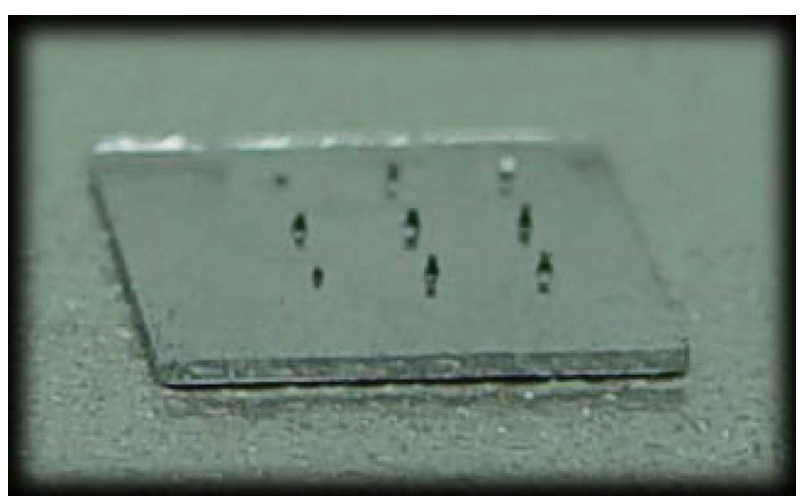

Fig. 8. The single microneedles array.

\section{Experimental Test}

The microneedles are mainly used for medical application. By destroying the cuticle, microneedles can increase the permeability and make the medicament easily infiltrate into the skin with painless.

In order to understand the use of microneedles, we utilize the microbalance to measure the weight before and after the using of microneedles. Figure 8 is the single microneedles array and the weight is $0.0212 \mathrm{~g}$. The microneedles array will be wetted with red ink and measured on microbalance to record the weight. Then the microneedles array is put on the artificial skin to make the ink infiltrate into the skin and the used microneedles array will be measured again by microbalance. Figure 9 shows the tested artificial skin and the red ink residues on the skin obviously.

During the twenty tests, we control the weight of micron-

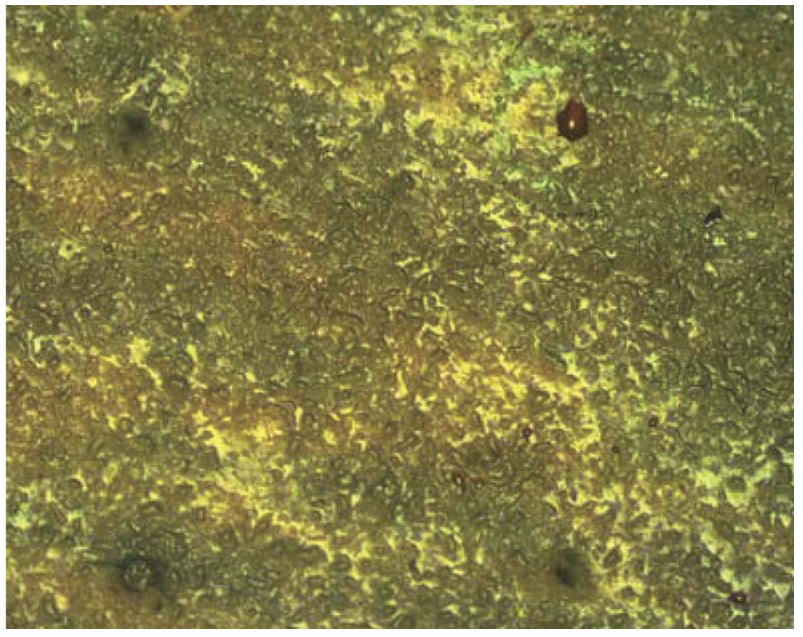

Fig. 9. The tested artificial skin.

Table 2. The experimental data of microneedles array.

\begin{tabular}{ccc}
\hline $\begin{array}{c}\text { Weight of } \\
\text { microneedles array } \\
\text { with red ink }\end{array}$ & $\begin{array}{c}\text { Used weight of } \\
\text { microneedles } \\
\text { array }\end{array}$ & $\begin{array}{c}\text { Residual } \\
\text { red ink on } \\
\text { skin }\end{array}$ \\
\hline 0.0241 & 0.0212 & 0.0029 \\
0.0246 & 0.0215 & 0.0031 \\
0.0248 & 0.0214 & 0.0034 \\
0.0243 & 0.0214 & 0.0034 \\
0.0236 & 0.0214 & 0.0022 \\
0.0241 & 0.0215 & 0.0026 \\
0.0249 & 0.0213 & 0.0036 \\
0.0252 & 0.0214 & 0.0038 \\
0.0241 & 0.0214 & 0.0027 \\
0.0253 & 0.0214 & 0.0039 \\
0.0238 & 0.0218 & 0.0020 \\
0.0239 & 0.0213 & 0.0026 \\
0.0238 & 0.0214 & 0.0024 \\
0.0250 & 0.0213 & 0.0037 \\
0.0247 & 0.0218 & 0.0029 \\
0.0239 & 0.0217 & 0.0025 \\
0.0238 & 0.0217 & 0.0021 \\
0.0243 & 0.0214 & 0.0029 \\
0.0252 & 0.0213 & 0.0039 \\
0.0240 & 0.0214 & 0.0026 \\
\hline & & \\
\hline
\end{tabular}

(Unit: g)

eedles array with red ink before using and the results show that the residual red ink on the artificial skin is average of about $0.003 \mathrm{~g}$ every time as listed in Table 2 . It is show that the microneedles array can make the liquid infiltrate into the skin uniformly.

\section{RESULTS AND DISCUSSION}

According to a series of design and fabrication process, we'll show the fabrication results as following. 


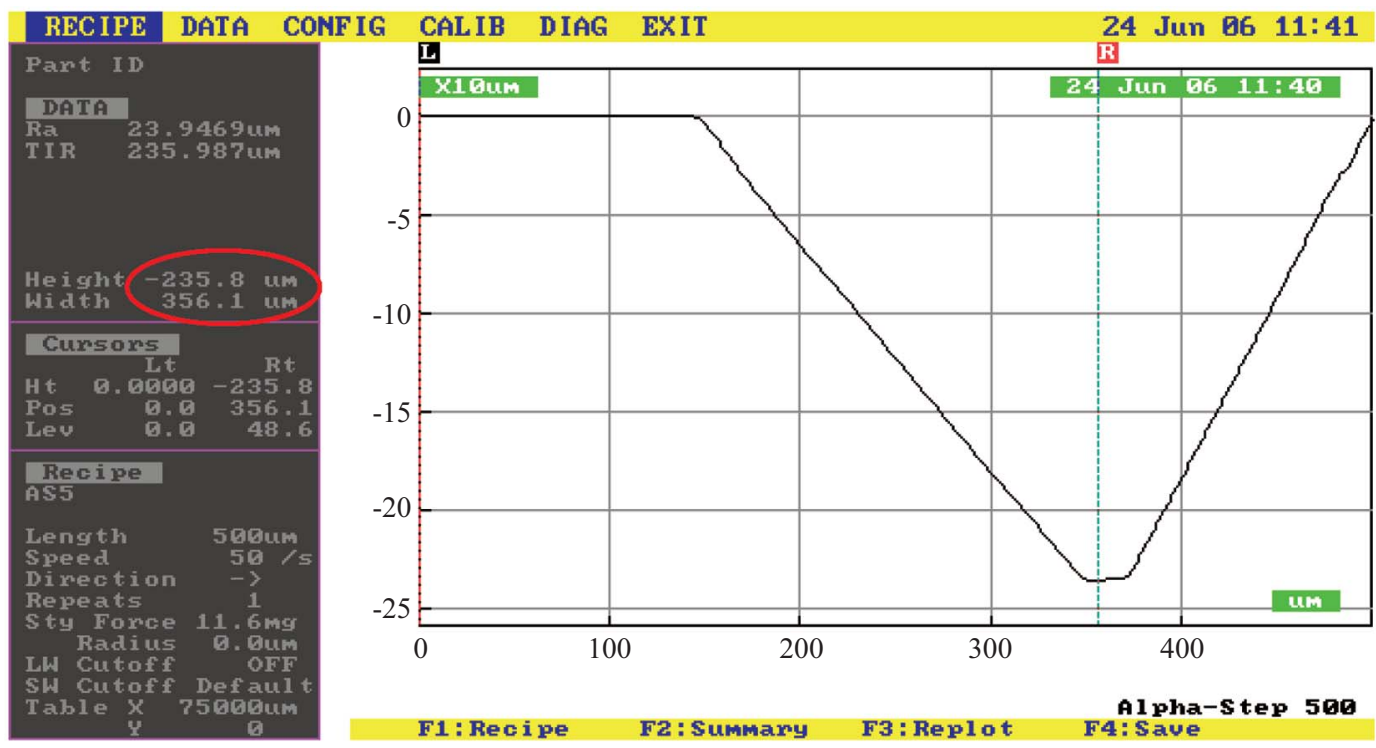

Fig. 10. The $\alpha$-step picture of the microneedles.

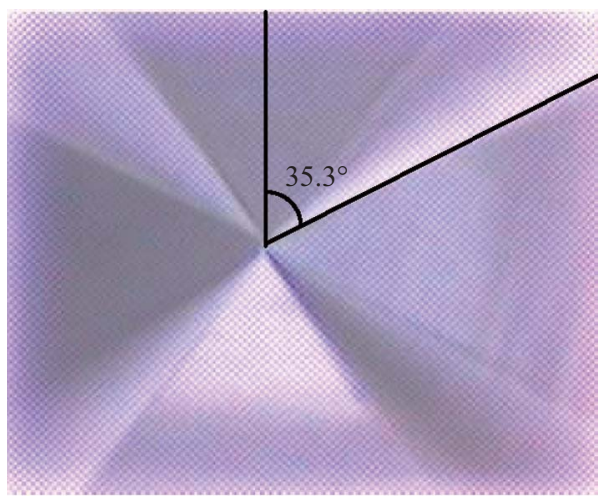

Fig. 11. The finished V-groove after etching.

\section{Polymer Microneedles}

At first, the $\mathrm{V}$-groove was fabricated by $\mathrm{KOH}$ solution and the etching rate is $16 \sim 20 \mu \mathrm{m} / \mathrm{h}$, Fig. 10 shows the $\alpha$-step picture of the microneedles and the height is $235.8 \mu \mathrm{m}$. Figure 11 is the finished V-groove after etching.

After etching, we'll cast the SU-8 photoresist on the silicon and develop the bottom of the microneedles shown in Fig. 12. The depth of SU-8 coating is $450 \mu \mathrm{m}$ and we have to keep an eye on the soft-bake, exposure and the baking after exposure to ensure it dry. Finally, the microneedles will be put in the MF-319 for the stripping and Fig. 13 is the SEM-photograph of microneedles.

\section{Silicon Microneedles}

The silicon microneedles should consider the accurate etching time. Only the exact time will form the microneedles.

Figure 14 is the SEM-photograph of silicon microneedles and the etching rate is $60 \mu \mathrm{m} / \mathrm{h}$.

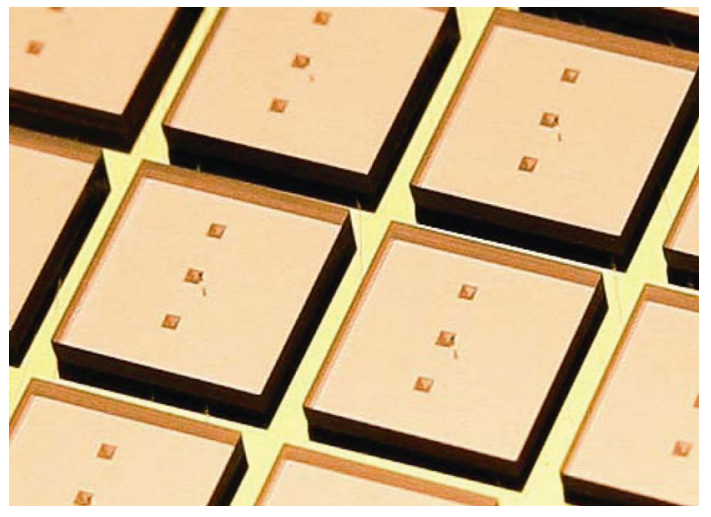

Fig. 12. The backside picture of microneedles before the stripping.

\section{CONCLUSION}

This study utilizes two different methods to fabricate the microneedles, polymer and silicon microneedles. The result of the purposed microneedles is to apply in the field of biomedicine technology.

We use these two different kinds of microneedles to test the permeability of the medicine throw the skins. By the destroying of the cuticle, the test reagent can permeate into the artificial skin uniformly. The total experimental results will provide advantage for the bio-medicine technology in the future.

\section{ACKNOWLEDGMENTS}

This work was supported by the National Science Council of Taiwan, Republic of China under contract NO. NSC-952221-E-237-003. 


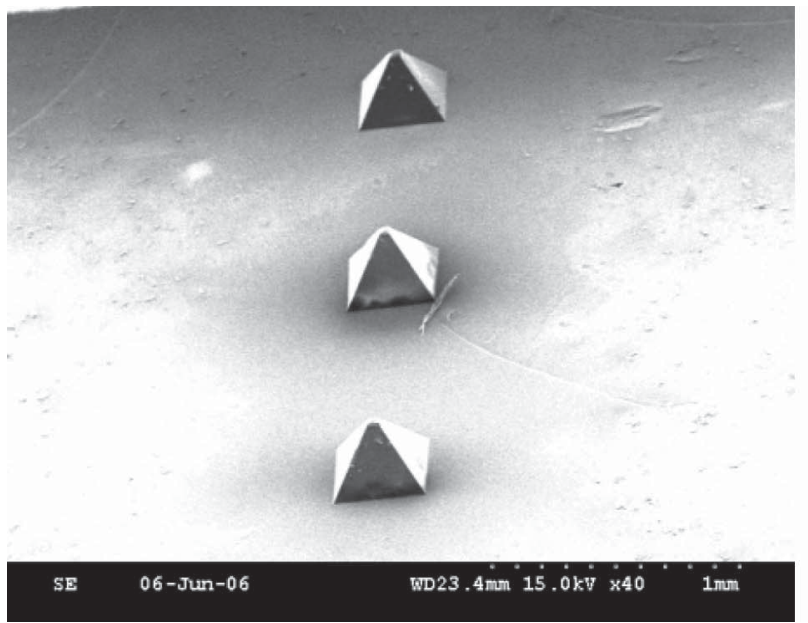

(a)

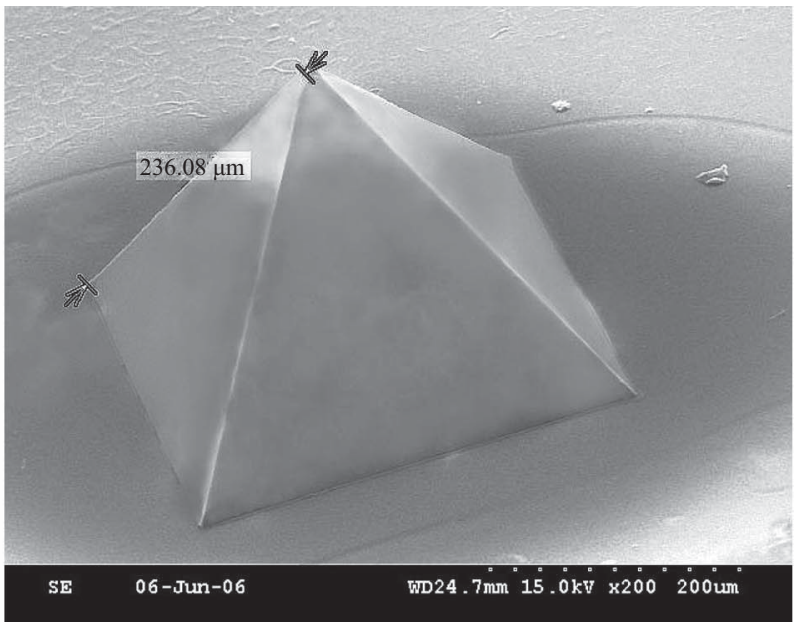

(b)

Fig. 13. The SEM-photograph of polymer microneedles: (a) the microneedles array, (b) the single microneedles.

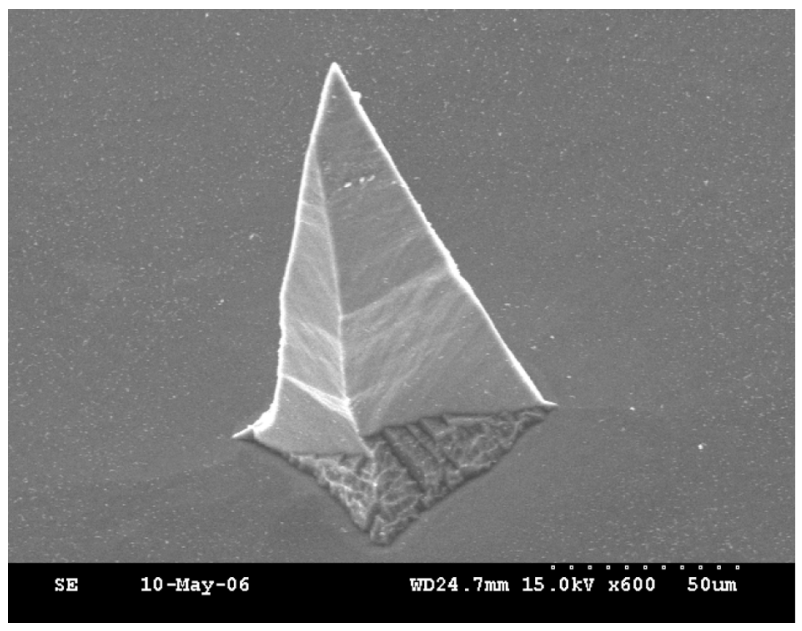

Fig. 14. The SEM- photograph of silicon microneedles.

\section{REFERENCES}

1. Guerin, L. J., Bossel, M., Calmes, S., Demierre, M., and Renaud, P., "Simple and low cost fabrication of embedded micro-channels by using a new thick-film photoplastic," TRANSDUCERS '97, Chicago, pp. 16-19 (1997).

2. Han, J. G. E. Gardeniers, Regina, L., Erwin, J. W. Berenschot, Meint J. de Boer Shuki Y. Yeshurun, Meir, Hefetz, Ronny, van't Oever, and Albert, van den Berg, "Silicon micromachined hollow microneedles for transdermal liquid transport," Journal of Microelectromechanical System, Vol. 12, pp. 855-862 (2003).

3. Kim, K., Park, D. S., Lu, H. M., Che, W., Kim, K., Lee, J. B., and Ahn, C. H., "A tapered hollow metallic microneedle array using backside exposure of SU-8," Journal of Micromechanics and Microengineering, Vol. 14, pp. 597-603 (2003).

4. Kuo, S. C. and Chou, Y., "A novel polymer microneedle and PDMS micromolding technique," Tamkang Journal of Science and Engineering, Vol. 7, pp. 95-98 (2004).

5. Lin, L. and Pisano, A. P., "Silicon-processed microneedles," Journal of Microelectromechanical System, Vol. 8, pp. 78-84 (1999).

6. Paik, S. J., Byun, S., Lim, J. M., Park, Y., Lee, A., Chung, S., Chang, J., Chun, K., and Cho, D., "Don", "In-plane single-crystal-silicon microneedles for minimally invasive microflud systems," Sensors and Actuators A: Physical, Vol. 114, pp. 276-284 (2004).

7. Wilke, N., Reed, M. L., and Morrissey, A., "The evolution from convex corner undercut towards microneedle formation: Theory and experimental verification," Journal of Micromechanics and Microengineering, Vol. 16, pp. 808-814 (2005). 